\title{
BMJ Open The future burden of obesity-related diseases in the 53 WHO European- Region countries and the impact of effective interventions: a modelling study
}

\author{
Laura Webber, ${ }^{1}$ Diana Divajeva, ${ }^{1}$ Tim Marsh, ${ }^{1}$ Klim McPherson, ${ }^{2}$ Martin Brown, ${ }^{1}$ \\ Gauden Galea, ${ }^{3}$ Joao Breda ${ }^{3}$
}

To cite: Webber L,

Divajeva D, Marsh T, et al. The future burden of obesityrelated diseases in the 53 WHO European-Region countries and the impact of effective interventions: a modelling study. BMJ Open 2014:4:e004787.

doi:10.1136/bmjopen-2014004787

- Prepublication history and additional material is available. To view please visit the journal (http://dx.doi.org/ 10.1136/bmjopen-2014004787).

JB and GG contributed equally to this study.

Received 3 January 2014 Revised 28 April 2014 Accepted 22 May 2014

CrossMark

For numbered affiliations see end of article.

Correspondence to

Dr Laura Webber;

laura.webber@ukhealthforum. org.uk

\section{ABSTRACT}

Objective: Non-communicable diseases (NCDs) are the biggest cause of death in Europe putting an unsustainable burden on already struggling health systems. Increases in obesity are a major cause of NCDs. This paper projects the future burden of coronary heart disease (CHD), stroke, type 2 diabetes and seven cancers by 2030 in 53 WHO European Region countries based on current and past body mass index (BMI) trends. It also tests the impact of obesity interventions on the future disease burden.

Setting and participants: Secondary data analysis of country-specific epidemiological data using a microsimulation modelling process.

Interventions: The effect of three hypothetical scenarios on the future burden of disease in 2030 was tested: baseline scenario, BMI trends go unchecked; intervention 1, population BMI decreases by $1 \%$; intervention 2, BMI decreases by $5 \%$.

\section{Primary and secondary outcome measures:}

Quantifying the future burden of major NCDs and the impact of interventions on this future disease burden.

Results: By 2030 in the whole of the European region, the prevalence of diabetes, CHD and stroke and cancers was projected to reach an average of 3990 , 4672 and 2046 cases/100 000, respectively. The highest prevalence of diabetes was predicted in Slovakia (10 870), CHD and stroke-in Greece (11 292) and cancers-in Finland (5615 cases/ $100000)$. A $5 \%$ fall in population BMI was projected to significantly reduce cumulative incidence of diseases. The largest reduction in diabetes and $\mathrm{CHD}$ and stroke was observed in Slovakia (3054 and 3369 cases/ 100000 , respectively), and in cancers was predicted in Germany (331/100 000).

Conclusions: Modelling future disease trends is a useful tool for policymakers so that they can allocate resources effectively and implement policies to prevent NCDs. Future research will allow real policy interventions to be tested; however, better surveillance data on NCDs and their risk factors are essential for research and policy.

\section{Strengths and limitations of this study}

- This study projects the future burden of obesity-related diseases using sophisticated microsimulation modelling software.

- It quantifies the impact on major chronic diseases (coronary heart disease, stroke, type 2 diabetes and cancers) given a $1 \%$ or $5 \%$ reduction in population body mass index.

- It highlights the need for good quality surveillance data for diseases and their risk factors so that accurate estimates can be made.

- The model does not take account of future changes in circumstances such as fluctuations in food prices or new medical technologies.

- The model is only as good as the data that are entered into it; with good quality data, more accurate predictions can be made.

\section{BACKGROUND}

Non-communicable diseases (NCD) such as cardiovascular and respiratory disease are the highest cause of death globally. ${ }^{1}$ In 2008 , the WHO estimated that mortality from heart disease, stroke, chronic lung disease, cancer and diabetes totalled 36.1 million. $^{2}$ The growing burden of NCDs warranted urgent political action. In September 2011 during the UN High-Level Meeting on NCDs, global leaders made a political declaration to provide a coordinated response for preventing and controlling NCDs. ${ }^{3}$ As a result, nine global voluntary targets aiming at combating global mortality from the four main NCDs, accelerating action against the leading risk factors for NCDs and strengthening national health system responses were set out. ${ }^{4}$

In the WHO European Region, NCDs are high on the WHO European Region agenda as they account for $86 \%$ of deaths and $77 \%$ 
of the disease burden. ${ }^{2}$ This burden is unequally distributed within and between the European countries: individuals from the most disadvantaged groups often have poorer access to healthcare and fewer resources such as education, employment and housing-all of which reduce the opportunities for healthy lifestyle choices. The new European health policy framework, Health 2020, highlights these inequalities and offers a road map for policymakers and public health professionals. ${ }^{5}$ The WHO European Region is determined to take forward the UN political declaration to reduce avoidable deaths from NCDs, turning the declaration into action, and are working to provide public health tools that help all countries across the broader European region to implement more effective programmes based on an extensive reflection process. ${ }^{5}$

The causes of NCDs may be genetic, behavioural and environmental. ${ }^{6}$ Rapid changes in health-related behaviours in recent decades have seen an upsurge in NCD prevalence ${ }^{7}$ through modifiable lifestyle factors such as diet and physical activity. Market forces driving down costs of high-calorie fatty, salty and sugary foods have made them cheap and readily available, resulting in increased consumption and expanding waistlines. In addition, advances in technology such as motorised transport, labour mechanisation and television have promoted sedentary lifestyles and reduced physical activity. ${ }^{8}$ Interventions that are able to tackle important risk factors such as obesity are likely to have a positive impact on NCD prevalence and premature mortality caused by NCDs.

Projections from the UK show that tackling risk factors associated with NCDs can substantially reduce morbidity from these diseases. For example, reducing body mass index (BMI) by $1 \%$ across the population (equivalent to $1 \mathrm{~kg}$ weight loss) was estimated to substantially reduce the health burden, saving 179000-202000 incident cases of type 2 diabetes, 122000 cases of cardiovascular diseases and 32 000-33000 incident cases of cancer over 20 years. ${ }^{9}$ Data from Russia show that obesity rates are predicted to increase to as high as $76 \%$ in men by 2050 , and rates of CHD and stroke will reach 12723 cases/ 100000 of the population. ${ }^{10}$ Similar projections have been implemented in other European countries, ${ }^{11}$ although to the best of our knowledge estimates of the future burden of obesity-related diseases in all European countries have not been carried out.

There is, therefore, a new threat menacing recent progress in NCD mortality and morbidity which needs to be quantified and the current study ignites this discussion within the context of health impact models. This study also hypothesises that while reduction in the burden of NCDs has been sustained, obesity is actually threatening those gains. As such, this study updates and extends this work by using a microsimulation model to project NCD trends to 2030 in all 53 European region countries and assesses the impact of two hypothetical interventions, intervention 1: a $1 \%$ reduction in population BMI and intervention 2: a $5 \%$ reduction in population BMI, on the future incidence of CHD and stroke, type 2 diabetes and obesity-related cancers.

\section{METHODS}

BMI data extraction

Online databases (Global database on BMI, ${ }^{12}$ European Union (EU) members' statistical office databases, PubMed $^{13}$ and Science Direct ${ }^{14}$ ) were searched for published data on age and sex-specific country obesity prevalence data presented according to WHO definitions of normal weight, overweight and obesity. ${ }^{12}$ In addition, article references were probed and individual researchers and public health officers were contacted for further data. A table of BMI references is presented in the online supplementary appendix 1 and methods of BMI data manipulation are explained in the online supplementary appendix $2 \mathrm{~A}$.

\section{Disease data sources}

A second review of statistical databases and literature was carried out to locate country-specific incidence, prevalence, survival and mortality data for CHD, stroke and obesity-related cancers (colorectal, pancreas, breast, kidney, liver, corpus uteri and oesophageal) as well as incidence and/or prevalence data for type 2 diabetes.

Where prevalence, but not incidence, data were available by age and sex, prevalence was converted to incidence using equations devised for DISMOD II software. ${ }^{15}$ Briefly, incidence is calculated from prevalence using a Downhill Simplex Method, ${ }^{16}$ where the algorithm determines the incidence iteratively using a best fit to the known prevalence.

Where neither incidence nor prevalence data were available, data from a proxy country were used. CHD incidence was often rare, so UK, Georgia, Spain, Russia and Uzbekistan incidence data were used as proxies for countries in a similar geographical location or countries which had comparable average prevalence rates. For example, for CHD data, Russian data were used as a proxy for Belarus; and Uzbekistan data were used for Kazakhstan, Kyrgyzstan, Tajikistan and Turkmenistan. Only Belarus, Denmark, Finland, Ireland, Norway, the Russian Federation and the UK had full sets of disease data. Furthermore, many countries required a proxy for survival data. Greater detail of which countries were used as proxies is presented in the online supplementary file, appendix 3. For fatal diseases, the ratio of the target-to-proxy countries' mortality rates was used to scale the proxy country's incidence rates. For type 2 diabetes, proxy country data were adjusted for the different population BMI distributions. For example, if country $\mathrm{x}$ had diabetes data and these were used as a proxy for country y where no data exist, then country y's BMI distribution would determine the future burden of type 2 diabetes via the relative risk.

For survival data, the probability of survival, p, for a number of years, $\mathrm{T}$, after acquiring a fatal disease was 
modelled in one of two ways depending on the disease: either as a simple exponential distribution $\mathrm{p}=\mathrm{e}^{-\mathrm{RT}}$, or as an exponential distribution allowing for different probability, $\mathrm{p}_{1}$, of survival in the first year, $\mathrm{p}=\mathrm{p}_{1} \mathrm{e}^{-\mathrm{R}(\mathrm{T}-1)}$. Stroke used the latter model while other fatal diseases used the former. Disease survival statistics consist of the rate $\mathrm{R}$ or the rate $\mathrm{R}$ together with the first year survival probability $\mathrm{p}_{1}$. These statistics can be further classified by age group and gender. The rate $\mathrm{R}$ was usually inferred from quoted 5-year survival statistics.

The relative risks of contracting each disease according to pre-obesity (BMI $25-29.9 \mathrm{~kg} / \mathrm{m}^{2}$ ) and obesity (BMI $30 \geq \mathrm{kg} / \mathrm{m}^{2}$ ) relative to normal weight (BMI 18.5$24.9 \mathrm{~kg} / \mathrm{m}^{2}$ ) with age and sex as covariates were taken from the International Association for the Study of Obesity. ${ }^{17} \mathrm{~A}$ table of disease references for each country is presented in the online supplementary file, appendix 3 .

\section{Statistical analysis}

Detailed statistical analysis is described in file, online supplementary appendix 2A,B, Foresight: Tackling Obesities $^{18}$ and Wang et al. ${ }^{9}$ Briefly, a dual-module modelling process was carried out: module one fits crosssectional BMI data from each country using a non-linear multivariate, categorical regression model. Module two creates virtual country cohorts of 5000000 individuals using a microsimulation method to produce longitudinal projections to 2030 based on module one BMI distributions. Microsimulation is a computer modelling technique that works at the level of the individual; it generates individual life histories of a specified population and this population reflects the age profile, birth, death and health statistics to make future projections. A BMI value is probabilistically assigned as a function of age, sex and calendar year and an individual's BMI percentile in the same age cohort is assumed to stay the same over time. Population size, births and deaths were also simulated in a large number of individuals as they age using data from the United Nations population statistics database. ${ }^{19}$ Population pyramids are presented in online supplementary appendix 4 . Within the simulation, individuals are at greater risk of getting a particular disease each year if he or she did not have the disease at the beginning of the year. Individuals can continue to live with the disease or die from it if it is fatal. The software for this program was written in $\mathrm{C}++.{ }^{20}$

To estimate the disease burden associated with the trends in pre-obesity and obesity, as well as the effect of possible interventions, future increases in obesity-related diseases were projected from 2010 to 2030, using three different trend interventions: baseline scenario: BMI trends go unchecked; intervention 1: mean population BMI decreases by $1 \%$ and intervention 2: mean population BMI decreases by $5 \%$. The cumulative incidence cases avoided for the whole of Europe were analysed by summing the weighted average of incidence for each country.

\section{RESULTS}

Only 36 countries had three or more years of BMI data. Less than or equal to two points of BMI data were available for the remaining 17 countries (Albania, Andorra, Belarus, Bosnia, Croatia, Cyprus, Georgia, Hungary, Macedonia, Monaco, Montenegro, Romania, San Marino, Serbia, Slovenia, Tajikistan and Turkmenistan), so results in this instance are interpreted with caution.

Alongside obesity, obesity-related diseases are projected to increase in almost all countries. Figure 1 presents the average projected prevalence rates for Europe (weighted for total population) by intervention. A $1 \%$ reduction in BMI would result in an average of 2110 cancers, $4690 \mathrm{CHD}$ and strokes, 3807 type 2 diabetes prevalence cases per 100000 of the population in Europe. For type 2 diabetes, this equates to a difference of 198 prevalence. This cases avoided per 100000 , a $4.7 \%$ reduction in prevalence. A $5 \%$ reduction in population BMI would result in an average of 3771 cases of type 2 diabetes by 2030 per 100000 of the population in 2010. This is a reduction in prevalence of 579 cases/ 100 000, equating to a $16.7 \%$ reduction across Europe.

Figure 2 shows the projected prevalence by 2030 of each disease by country per 100000 of the population in 2010. There was a wide variability between countries. The highest projected prevalence of cancers was observed in Finland with 5615 cases/100 000 of the population in 2010. The highest projected prevalence of CHD and stroke was observed in Greece with 11292 cases and the highest projected prevalence of type 2 diabetes was in Slovakia with 10870 cases/100 000 of the population in 2010.

Figure 3 presents the European average cumulative incidence gains by 2030 for each disease, given a $1 \%$ or $5 \%$ reduction in population BMI relative to the baseline scenario. As expected, higher reductions of population BMI would result in a number of obesity-related disease cases being avoided by 2030 . A $1 \%$ reduction in BMI would result in an average reduction of 365 cases of CHD and stroke per 100000 of the population by 2030 . A $5 \%$ reduction in population BMI would result in the avoidance of 1317 cumulative incidence cases of CHD and stroke per 100000 of the population.

Figure 4 presents cumulative incidence cases avoided in each of the 53 WHO European region countries if population BMI is reduced by $5 \%$. The highest reduction in CHD and stroke and type 2 diabetes was predicted in Slovakia with 3054 and 3369 cumulative incidence cases per 100000 population avoided by 2030 , respectively. The highest reduction in cumulative incidence of obesity-related cancers was projected in Germany with 331 cases/100 000 avoided by 2030 .

Data tables for each country displaying cumulative incidence cases, cumulative incidence cases avoided, prevalence cases and prevalence cases avoided per 100000 of the population are presented in online supplementary appendix 5 . 


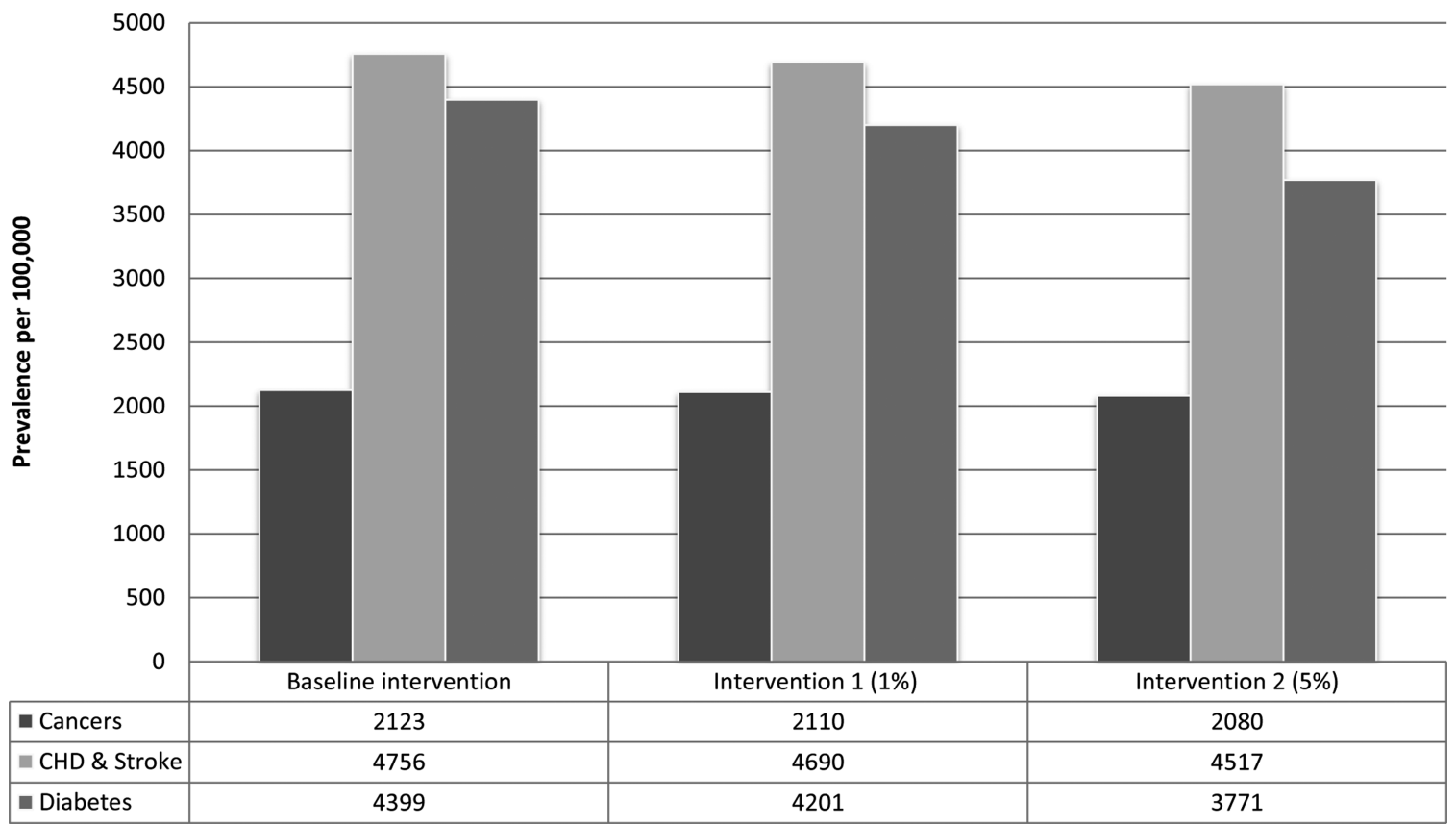

Figure 1 Total projected prevalence by 2030 per 100000 of the population for 53 WHO European Region Member States (CHD, coronary heart disease).

\section{CONCLUSIONS}

This study used a microsimulation model to test the impact of effective interventions that reduce population BMI on the future burden of disease. With only a few exceptions, obesity rates across the 53 countries were projected to increase by 2030. This is worrying, given the extent of the related disease burden associated with obesity. There appeared to be very little pattern to the projected disease trends regionally across Europe. One important reason for this is due to the paucity of disease data across the region and the need to use proxy data for many diseases, making specific comparisons between countries difficult.

Owing to the increasing obesity trends, our findings suggest that in 20 years an increasing number of people will be living with an obesity-related chronic disease in almost every country in Europe. Birth rates are low across Europe with most total fertility rates (TFR) below 2. This means that the population is ageing with fewer young people. Only Azerbaijan (2.12), Israel (2.62), Tajikistan (3.13) and Uzbekistan (2.19) have TFRs above 2. Projecting further, we may observe a dip in prevalence rates as those with the disease die while there are fewer younger people to contract the disease. Differences in the population profiles across countries may therefore result in different estimates even if the current disease incidence is comparable. Population profiles for each country are illustrated in appendix 5 of the online supplementary information.

Obesity-related cancers are rare and have relatively low rates compared with the other diseases. However, rates are projected to increase. Recent trends in cancer survival across Europe between 2000 and 2004 reported that the survival of breast cancer was lower in Central-Europe (Poland, Estonia and Slovenia) than elsewhere in Europe. ${ }^{21}$ Screening and medical advances and varied access to effective treatment are likely to account for differences between central, eastern and western regions in Europe.

Obesity is closely linked with insulin resistance and recent years have seen an epidemic of type 2 diabetes evolve alongside rapid increases in obesity. In the UK alone, a continued increase in obesity is projected to add 6-8.5 million incidence cases of type 2 diabetes by 2030 , at a substantial cost to the UK health system. ${ }^{9}$ Rates of CHD and stroke too were projected to increase across most countries. The highest prevalence rates were seen in Greece (11292/100 000 population) and the lowest in Spain (1030/100 000 population). However, since very little CHD data were available, UK data were often used as a proxy, possibly underestimating the rates of CHD in Europe. Where data were available (eg, Ireland and Finland), much higher rates were predicted, suggesting that rates may be underestimated when using UK data and interpretation of proxy data should be made with caution. Data for stroke incidence were mostly taken from estimates by Truelsen et al. ${ }^{22}$ These data were compared with Estonia from the 2007 Tartu stroke registry ${ }^{23}$ and appear to be slightly inflated. Similarly, rates were higher in the Truelsen estimates compared with Polish data from 2005-2006, so rates of stroke incidence may be slightly overestimated.

Quantification of the burden of NCDs is important to patients and public health professionals because of the long-term consequences to patients' functioning and demand for healthcare. ${ }^{24}$ However, quantification via 


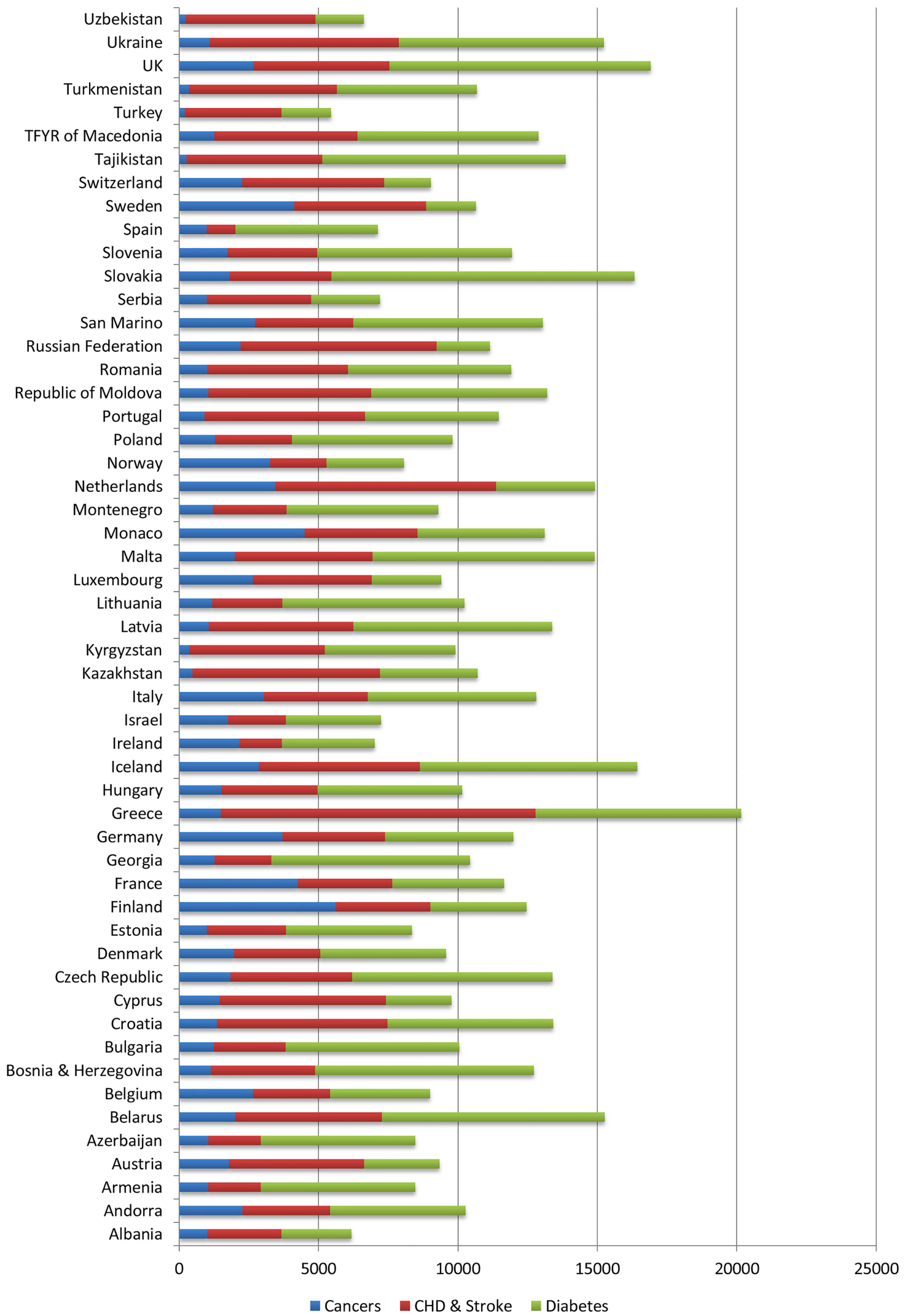

Figure 2 Projected prevalence of cancers, diabetes, coronary heart disease (CHD) and stroke, per 100000 of the population by 2030 by country.

microsimulation is dependent on good-quality surveillance data. The present study highlights the lack of up-to-date surveillance data-especially annual measured BMI and disease incidence data, which are measured using a consistent methodology. These data are necessary if national policies to control NCDs are to be appraised objectively. 


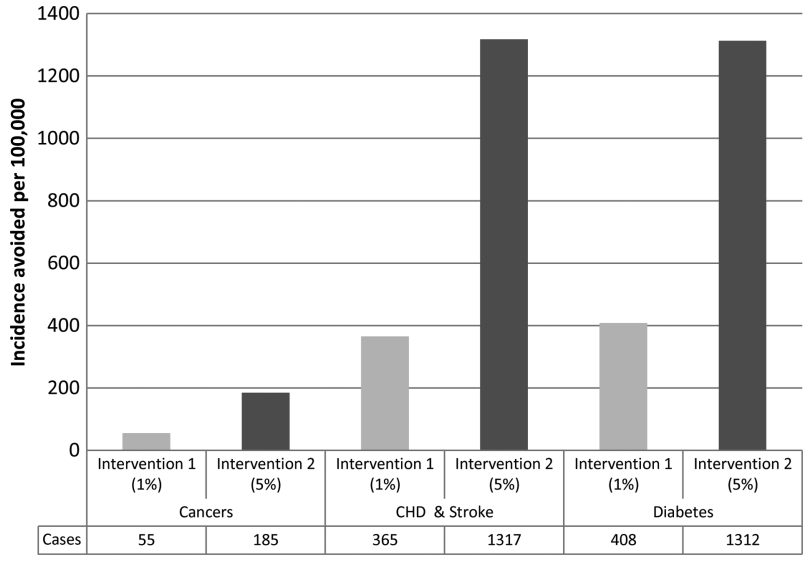

Figure 3 Cumulative incidence cases avoided by 2030 by disease given a $1 \%$ or $5 \%$ reduction in population body mass index relative to the baseline scenario in 53 WHO European Region Member States. CHD, coronary heart disease.

For some countries no satisfactory BMI data were available, so proxy country data were used (in the case of Member States with very small populations) or extrapolated from mean data (in the case of other countries). Some of the trends shown by the analysis have large confidence intervals due to the small number of data points used as well as the small sample sizes of some of the studies, and therefore the observed trends can only be indicative. Ideally, the data should be measured, but for most countries the only studies available were the ones in which anthropometry had been self-reported. This weakens the analysis, particularly if used in combination with measured data, because people tend to under-report their weight in interviews or surveys. $^{25}$

Relative risk data may also be limited in the extent to which they estimate the true impact of BMI on disease. Relative risks were taken from the International Association for the Study of Obesity ${ }^{16}$ as these were deemed to be the best available at the time of development of the country models. However, there are limitations to these risks due to the lack of suitable meta-analyses used to calculate them. They are also based on measured and self-reported data and do not account for ethnic differences in body composition since they are based on largely Caucasian populations. In the present study, we included the same relative risk for each Member State; however, given the lack of epidemiological data on BMI and disease within many of the countries of interest, it is unknown whether this assumption is valid.

Increased surveillance and monitoring of NCDs is one of the priorities of the Global Action Plan for Prevention and Control of Noncommunicable diseases 2013-2020. ${ }^{26}$ This strategy aims to target governments in making policies that control and abate the increasing prevalence of NCDs across Europe and our results provide further evidence for raising the priority of NCD prevention. In particular, this study promotes the need for interventions that are effective in reducing major NCD risk factors (objective 3 of the strategy). In addition to this, in early 2013, the WHO formed a global monitoring framework which aims to track the progress of prevention of major NCDs and their key risk factors and consists of 9 global targets and 25 indicators adopted by the WHO Member States during the 66th World Health Assembly in May 2013.

The microsimulation models are easily adaptable to include new data when it becomes available from such strategies. For example, we were not able to include data on children because of the limited amount of standardised data, but with initiatives such as the WHO Childhood Obesity Surveillance Initiative, ${ }^{27}$ assessment of future childhood obesity trends will be possible.

This study tested hypothetical and largely aspirational scenarios. However, it serves to demonstrate the value of modelling to quantify the estimated future health burden of risk factors. If data are available, the model can test the long-term effectiveness of real policy interventions and future work aims to do this. ${ }^{28}$

A key assumption of the model is that people do not reverse in the BMI categories. At a population level this generally reflects reality, where weight loss is often only temporary. However, this assumption does not take into account future changes in circumstances, such as fluctuations in food prices. It relies on our best estimate based on previous trends. That said, this approach allows for future trends to be forecast so that policymakers can plan interventions and allocate resources appropriately.

It is clear that tackling NCDs is a major challenge across Europe placing unsustainable burden on struggling health systems. This study provides a picture of the future with projections, and observes a worsening situation with increasing incidence of obesity-related disease. As a result, these findings call for governments to plan ahead and initiate change that effectively reduces key risk factors like obesity through preventative measures such as price policies, industry pledges and reduced marketing of foods high in fat, sugar and salt. Primary prevention is crucial if increasing trends are to be averted. ${ }^{29}$

\section{Panel: Research in context}

Non-communicable diseases (NCD) are the biggest cause of death in Europe. Health impact models are a useful and important policy tool enabling measurement of the future burden of NCDs. Obesity is a major modifiable risk factor for NCDs, which makes it necessary to quantify this threat. The current study explored the future impact of changing trends in BMI on the future burden of NCDs to 2030. Effective interventions that successfully reduce population BMI by $1 \%$ or $5 \%$ would have a significant impact on obesity-related diseases such as cardiovascular disease, type 2 diabetes and some cancers.

Microsimulation modelling should be utilised by policymakers so that they can plan for the future provision 


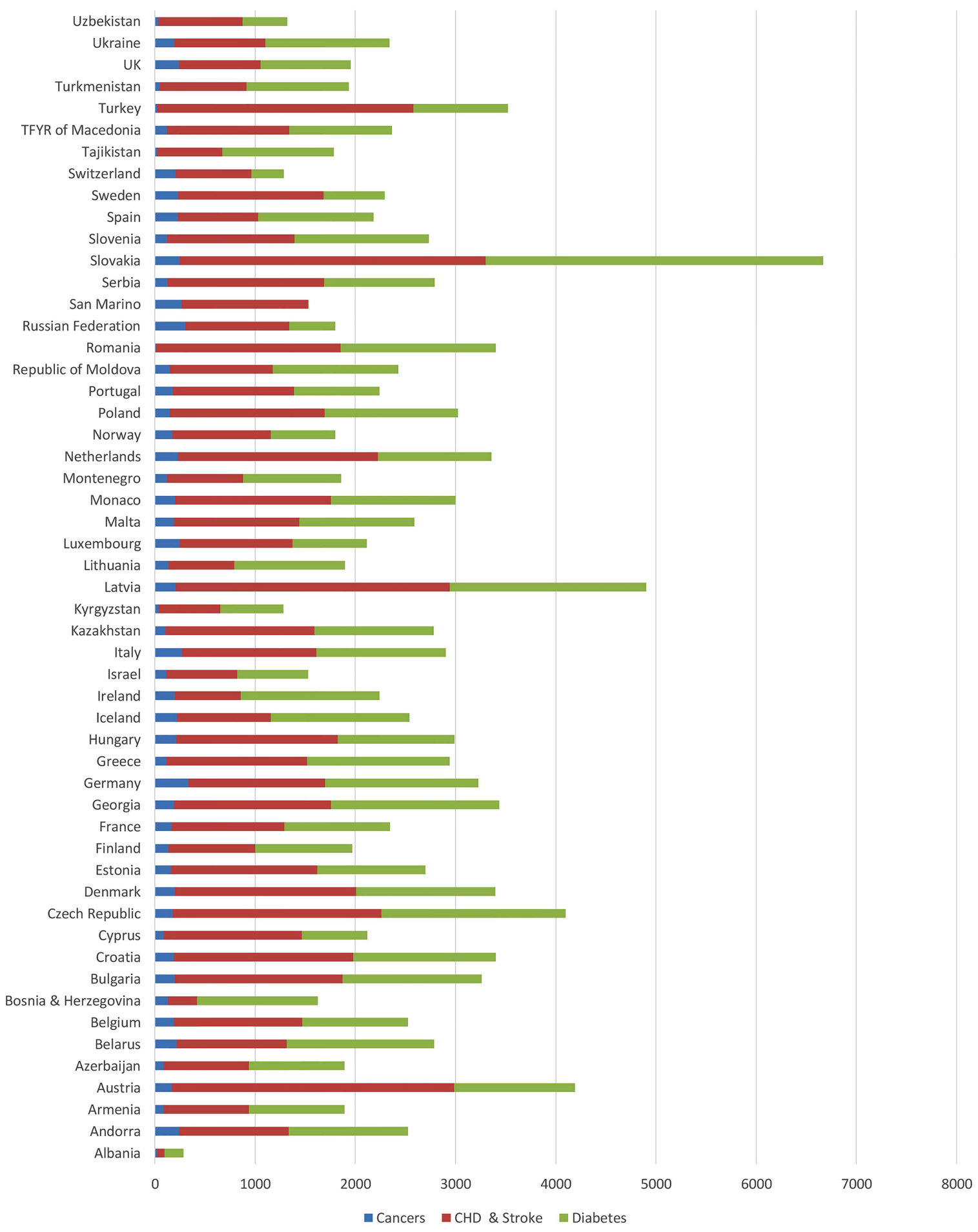

Figure 4 Projected cumulative incidence cases avoided by 2030 per 100000 of the population by country given a $5 \%$ reduction in population body mass index (CHD, coronary heart disease).

of healthcare resources and instigate and maintain interventions that prevent the onset of debilitating NCDs at both an individual and national level.

Author affiliations

${ }^{1}$ Modelling Department, UK Health Forum, London, UK

${ }^{2}$ New College, University of Oxford, Oxford, UK

${ }^{3}$ Division of Noncommunicable Diseases and Life-Course, WHO Regional

Office for Europe, Copenhagen, Denmark
Contributors LW and DD carried out the acquisition, analysis and interpretation of data for the work in this study and drafted the manuscript. $\mathrm{TM}, \mathrm{JB}, \mathrm{KM}$ and $\mathrm{GG}$ contributed to the conception and design of this study. $J B, G G, T M, M B$ and $K M$ revised the document for important intellectual content. All the authors edited and approved the final version of this manuscript and agree to be accountable for all aspects of the work in ensuring that questions related to the accuracy or integrity of any part of the work are appropriately investigated and resolved.

Funding This study was co-funded by a grant provided by the European Commission to the WHO Regional Office for Europe. 
Competing interests None.

Disclaimer GG and JB are staff members of the WHO. The authors alone are responsible for the content and writing of this paper, which does not necessarily represent the views of the World Health Organization.

Provenance and peer review Not commissioned; externally peer reviewed.

Data sharing statement Data used in these analyses are from published sources and can be accessed on request (laura.webber@ukhealthforum.org.uk).

Open Access This is an Open Access article distributed in accordance with the Creative Commons Attribution Non Commercial (CC BY-NC 3.0) license, which permits others to distribute, remix, adapt, build upon this work noncommercially, and license their derivative works on different terms, provided the original work is properly cited and the use is non-commercial. See: http:// creativecommons.org/licenses/by-nc/3.0/

\section{REFERENCES}

1. Imperial College London. Global Burden of Metabolic Risk Factors of Chronic Diseases. http://www5.imperial.ac.uk/medicine/metabolic_ risks/bmi/ (accessed 20 May 2013).

2. World Health Organization. Global Status Report on NCDs. http://www. who.int/chp/ncd_global_status_report/en/(accessed 15 Apr 2013).

3. General Assembly of the United Nations. UN High Level Meeting Non-Communicable Diseases. http://www.un.org/en/ga/president/65/ issues/ncdiseases.shtml (accessed 1 Jun 2013).

4. World Health Organization. NCD Global Monitoring Framework. http://www.who.int/nmh/global_monitoring_framework/en/ (accessed 1 Jun 2013).

5. World Health Organization Regional Office for Europe. The new European policy for health. Health 2020: vision, values, main directions and approaches. http://www.euro.who.int/_data/assets/pdf_file/0007/ 147724/wd09E_Health2020_111332.pdf (accessed 4 Jun 2013).

6. Shuldiner AR. Obesity genes and gene-environment-behavior interactions: recommendations for a way forward. Obesity 2008;16 (Suppl 3):S79-81.

7. World Health Organization. Diet, Nutrition and the prevention of Chronic Disease. 2003. http://whqlibdoc.who.int/trs/who_trs_916.pdf (accessed 10 Feb 2013).

8. Jones A, Bentham G, Foster C, et al. Foresight tackling obesities: future choices-obesogenic environments-evidence review. Government Office for Science, 2007. http://www.bis.gov.uk/assets/ foresight/docs/obesity/03.pdf (accessed 23 Jan 2013).

9. Wang YC, McPherson K, Marsh T, et al. Health and economic burden of the projected obesity trends in the USA and the UK. Lancet 2011:378:815-25.

10. Rtveladze K, Marsh T, Webber L, et al. Obesity trends in Russia. The impact on health and healthcare costs. Health 2012;4:1471-84.

11. Webber L, Kilpi F, Marsh T, et al. Modelling obesity trends and related diseases in Eastern Europe. Obes Rev 2012;13:744-51.
12. World Health Organization. Global database on body mass index. http://apps.who.int/bmi/ (accessed 3 Mar 2012).

13. National Institute of Health. Pubmed.gov US National Library of Medicine. http://www.ncbi.nlm.nih.gov/pubmed (accessed 2 Mar 2013).

14. Elsevier. Science Direct. http://www.sciencedirect.com (accessed 15 Jun 2012)

15. World Health Organization. DISMOD II. http://www.who.int/ healthinfo/global_burden_disease/tools_software/en/ (accessed 28 Nov 2012)

16. Nelder JA, Mead R. A simplex method for function minimization. Comput J 1965;7:308-13.

17. International Association for the Study of Obesity. Estimated relative risk of disease by BMI category: overweight and obesity. http://www. iaso.org/site_media/uploads/Appendix_Relative_Risk_ Assessments_IASO.pdf (accessed 20 Nov 2012).

18. McPherson K, Marsh KT, Brown M. Foresight report on obesity. Lancet 2007;37:1755.

19. United Nations Department of Economics and Social Affairs. World Population Prospects, the 2010 Revision. http://esa.un.org/wpp/ (accessed 10 Jun 2012).

20. Embarcadero Technologies. embarcadero. http://www.embarcadero. co.uk/ (accessed 10 Jun 2013)

21. Gondos A, Bray F, Brewster DH, et al. Recent trends in cancer survival across Europe between 2000 and 2004: a model-based period analysis from 12 cancer registries. Eur $\mathrm{J}$ Cancer 2008;44:1463-75.

22. Truelsen TP, Piechowski-Jóźwiak B, Bonita R, et al. Stroke incidence and prevalence in Europe: a review of available data. Eur J Neurol 2006;13:581-98.

23. Vibo R, Korv J, Roose M. The third stroke registry in Tartu, Estonia, from 2001 to 2003. Acta Neurol Scand 2007;116:31-6.

24. van den Bos GAM. The burden of chronic diseases in terms of disability, use of health care and healthy life expectancies. Eur $J$ Public Health 1995;5:29-34.

25. Visscher TL, Viet AL, Kroesbergen IH, et al. Underreporting of $\mathrm{BMI}$ in adults and its effect on obesity prevalence estimations in the period 1998 to 2001. Obesity (Silver Spring) 2006;14: 2054-63.

26. World Health Organization. Global Action Plan for the control of noncommuinicable diseases 2013-2020. Geneva, Switzerland: WHO document production services. http://apps.who.int/iris/bitstream/ 10665/94384/1/9789241506236_eng.pdf (accessed 25 June 2014).

27. Health Organization. Childhood Obesity Surveillance Initiative. http:// www.euro.who.int/en/what-we-do/health-topics/disease-prevention/ nutrition/activities/monitoring-and-surveillance/ who-european-childhood-obesity-surveillance-initiative-cosi (accessed 2 May 2012).

28. Economics of chronic diseases. Project overview. http://www. econdaproject.eu/ (accessed 14 Jan 2014).

29. World Health Organization. Global Status Report on NCDs 2011chapter 7. http://www.who.int/chp/ncd global_status_report/en/ (accessed 2 Jun 2013). 